\title{
Reaction of Hardened Portland Cement Paste With Carbon Dioxide
}

\author{
Charles M. Hunt and Lewis A. Tomes ${ }^{1}$
}

(July 23, 1962)

\begin{abstract}
The effect of age, water-cement ratio, and evaporable-water content on the reaction of hardened cement paste with carbon dioxide was investigated, using small cylinders of cement paste. The rate and extent of the reaction are subject to manipulation by varying the evaporable water content of the paste. Pastes of different age and water-cement ratio tend to dry at different rates, and this difference exerts an important indirect effect on carbonation.

Analysis of the specimens showed that less than one molecule of nonevaporable water was released for every molecule of carbon dioxide gained, except in paste of low watercement ratio or at low levels of carbonation in other pastes. If calcium hydroxide were the only phase attacked, equimolecular $\mathrm{CO}_{2}-\mathrm{H}_{2} \mathrm{O}$ stoichiometry would be expected. The observed behavior does not rule out the possibility of some preferential attack on calcium hydroxide, but other phases can react while calcium hydroxide is still present. Watercement ratio, particularly in very dense paste, may exert some effect on the comparative accessibility of different phases.
\end{abstract}

\section{Introduction}

Practical interest in the carbonation of hydrated portland cement stems from the fact that it modifies the properties of cement products. It usually improves the compressive strength $[1-6],{ }^{2}$ but carbonation under some circumstances has been reported to be deleterious [7]. Jones [4] found the impact strength of cement-asbestos sheet to be adversely affected by carbonation. Also, water containing carbon dioxide may attack gel constituents and weaken concrete under prolonged exposure [8a]. When concrete, mortar, or hardened cement paste is allowed to react with carbon dioxide, shrinkage is observed [3, 9, 10,11], but the carbonated product may exhibit somewhat greater volume stability than the original material $[10,11]$. Carbonation has also been discussed as a possible cause of the crazing observed on some concrete surfaces [1,8b].

The reaction of cement products with carbon dioxide is influenced by the colloidal structure of cement paste. It is partly a diffusion-controlled process in which water functions primarily as a barrier to the rapid movement of gas, and it is partly a moisture-controlled process in which a small amount of water is necessary before reaction will take place. Bessey [2] observed that the carbonation of mortar and sand-lime specimens proceeded more readily as the relative humidity of exposure was lowered. Lea and Desch [6] in discussing this behavior suggested that the rate of carbonation probably falls off again at some still lower relative humidity. There is now ample published experimental evidence to support this view $[10,12,13]$. The present paper describes some experiments with

1 Research associate representing the Calcium Chloride Institute at the National Bureau of Standards.

2 Figures in brackets indicate the literature references at the end of this paper. small specimens of paste, which examine in some detail the effect of age, water-cement ratio, and evaporable water content on the reaction of hydrated portland cement with carbon dioxide. Carbonation is considered primarily from the point of view of the water and carbon dioxide involved in the overall process.

\section{Methods and Materials}

\subsection{Cements}

Two cements were used for these experiments. Both met the requirements of Federal Specification SS-C-192 for type I cement. The chemical analysis of the cements is given in table 1. Cement No. 1 was used in the depth-of-penetration study. Cement No. 6 was used in all other experiments.

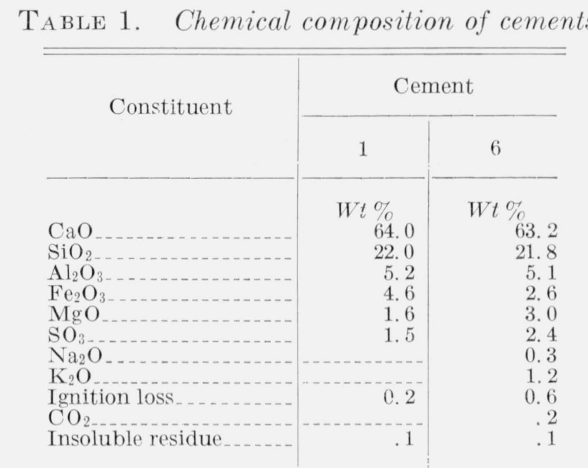

\subsection{Preparation of Specimens}

Thirty to forty grams of cement were mixed with water and cast in cylindrical polystyrene molds, $1 / 2$ in. in diameter and $1 / 2$ in. deep. Nominal water-cement ratios of $0.3,0.4$, and 0.5 were selected, and an addi- 
tional serıes of specimens of water-cement ratio 0.5 were prepared in which 1.56 percent of the cement was replaced with $\mathrm{CaCl}_{2}$.

Curing for the first $24 \mathrm{hr}$ took place in sealed molds. Curing beyond $24 \mathrm{hr}$ took place in paraffin sealed glass jars containing a small amount of water in the bottom to maintain high relative humidity. The specimens were exposed to the vapor only.

Specimens for the measurement of depth of carbonation were cast in glass tubes 1 in. in diameter and $2 \frac{1}{2}$ in. deep. A nominal water-cement ratio of 0.5 was used. They were cured and allowed to remain in the tubes, so that the subsequent loss of water and gain of carbon dioxide were essentially unidirectional through the top surface. Samples for analysis were taken with a masonry drill, and sampling depths were measured with a depth gauge.

\subsection{Carbonation of Specimens}

Ten specimens were taken to represent each age and water-cement ratio. The specimens in each series are designated here by numbers 1 through 10 , and the precarbonation treatment of each specimen is summarized as follows:

1. Placed in water $10 \mathrm{~min}$ and surface blotted.

2. No treatment.

3. Vacuum dried $1 / 2 \mathrm{hr}$.

4. Vacuum dried $2 \mathrm{hr}$.

5. Vacuum dried $5 \mathrm{hr}$.

6. Vacuum dried $24 \mathrm{hr}$.

7. Vacuum dried $72 \mathrm{hr}$.

8. Vacuum dried 7 days.

9. Vacuum dried 7 days after which the specimen was crushed and vacuum dried an additional 7 days.

10. No treatment and not exposed to carbon dioxide.

After pretreatment, specimens 1 through 9 were exposed to dried carbon dioxide at one atmosphere for a week in closed individual cells similar to the one illustrated in figure 1 . The ambient temperature during exposure was $25^{\circ} \mathrm{C}$. Specimen 10 was not dried or exposed to carbon dioxide and served as a check on the normal rate of hydration of the paste during the 1-week exposure period.

The depth-of-carbonation specimens, arbitrarily designated $\mathrm{A}, \mathrm{B}, \mathrm{C}$, and $\mathrm{D}$, were vacuum dried for periods of $30 \mathrm{~min}, 6 \mathrm{hr}, 48 \mathrm{hr}$, and 7 days respectively. They were then exposed to carbon dioxide at 1 atm for a week in a glass jar equipped with a gas inlet trap containing $n$-butyl phthalate, similar to the one in figure 1.

\subsection{Determination of Nonevaporable Water, Evap- orable Water, and Carbon Dioxide}

Nonevaporable water, $W_{n}$, was determined by a slight modification of the Copeland and Hayes procedure [14]. After exposure to carbon dioxide, the specimens were dried in a vacuum system containing a trap cooled with dry ice. The period of drying was selected so as to give each specimen a week of drying, including any drying received before carbonation.

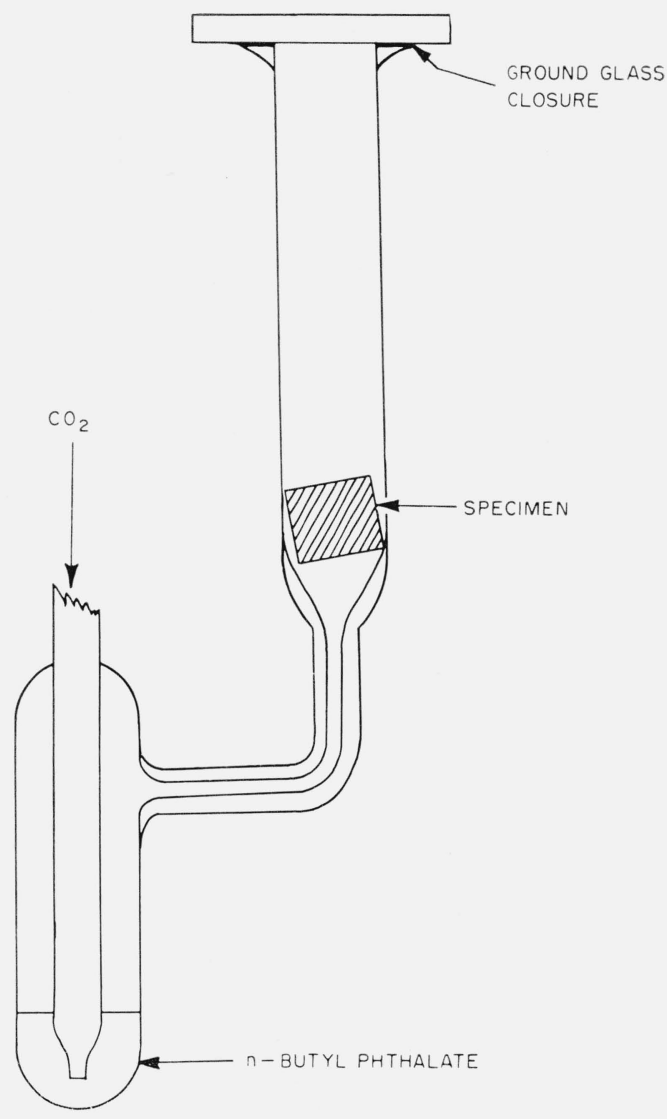

Figure 1. Cell for exposing cylinders of hardened cement paste to carbon dioxide.

The specimens were then crushed and dried for an additional week. The number 9 specimen of each series, which received this complete drying treatment before exposure to carbon dioxide, was given an additional $24 \mathrm{hr}$ of drying after carbonation to compensate for the extra handling. Nonevaporable water was then determined by measuring the loss of weight at $1,050{ }^{\circ} \mathrm{C}$ and subtracting the carbon dioxide content of the specimen.

Evaporable water, $W_{e}$, was determined by measuring the loss in weight of each specimen during precarbonation drying and subtracting this loss from the total evaporable water content of the original hardened paste. The water lost by the number 9 specimen of each series was assumed to represent the total evaporable water content of the original paste.

Carbon dioxide was determined by digesting the paste in 4-normal hydrochloric acid and absorbing the evolved gas in Ascarite. The apparatus and procedure were similar to those described by Kolthoff and Sandell [15] with minor modifications which have been previously described [16].

\subsection{Estimation of Pore Volume}

Total pore volume, $P_{T}$, and gel pore volume, $P_{G}$, of the original hardened paste were calculated from the equations of Copeland and Hayes [17], 


$$
\begin{aligned}
& P_{T}=0.99\left(W_{o}-0.746 W_{n}\right) \\
& P_{G}=2.36 k W_{n}
\end{aligned}
$$

where $W_{0}$ is the original mixing water and represents the total pore volume at the start of hydration, $k$ is a constant for any given cement, and $\dot{W}_{n}$ is the nonevaporable water content of the original paste. In the present experiments $W_{o}$ was based on the total water in the paste immediately after removal from the mold after $24 \mathrm{hr}, k$ was assumed to be 0.3 , and $W_{n}$ was based on the nonevaporable water content of the number 9 specimen of each series after carbonation. Such values of $W_{n}$ are estimated to be 0.2 to 0.5 percent less than the true nonevaporable water content of the original paste. An uncertainty of 0.5 percent in $W_{n}$ corresponds to an uncertainty in total pore volume of about $0.4 \mathrm{ml}$ per hundred grams of ignited cement. Also, the equations of Copeland and Hayes are based upon vacuum-mixed pastes and would not include any entrained air in the specimens.

\section{Results and Discussion}

\subsection{Effect of Predrying on Carbonation}

The results obtained when $1 / 2$-in. specimens of hardened cement paste of different age and water-cement ratio were partially dried and allowed to react with carbon dioxide are summarized in table 2 . The data include evaporable water content before exposure to carbon dioxide and carbon dioxide and nonevaporable water content after exposure. Wide variations in the amount of carbon dioxide reacting with the pastes are evident in the table. Individual specimens contain as little as 0.82 or as much as 40.65 percent carbon dioxide after a week in an atmosphere of the gas. It is clear that the reaction is extremely responsive to the drying treatment received by the paste before exposure.

The effect of predrying is shown more clearly in figure 2 where carbon dioxide content is plotted as a function of drying time. Each age and water-

TABLE 2. Evaporable water content of cement pastes before exposure to carbon dioxide and the nonevaporable water and carbon

\begin{tabular}{|c|c|c|c|c|c|c|c|c|c|c|c|}
\hline \multirow{3}{*}{$\begin{array}{l}\text { Nominal } \\
\text { w/c ratio }\end{array}$} & \multirow{3}{*}{$\begin{array}{l}\text { Specimen } \\
\text { number }\end{array}$} & \multirow[b]{2}{*}{$\begin{array}{c}\text { Original } \\
\text { mixing } \\
\text { water } W_{o}\end{array}$} & \multicolumn{3}{|c|}{ 1-day hydration } & \multicolumn{3}{|c|}{ 7-day hydration } & \multicolumn{3}{|c|}{ 28-day hydration } \\
\hline & & & $\begin{array}{c}W_{e} \text { evap. } \\
\mathrm{H}_{2} \mathrm{O} \text { before } \\
\text { exposure }\end{array}$ & $\begin{array}{c}W_{n} \\
\text { nonevap. } \\
\mathrm{H}_{2} \mathrm{O} \text { after } \\
\text { exposure }\end{array}$ & $\begin{array}{l}\mathrm{CO}_{2} \text { after } \\
\text { exposure }\end{array}$ & $\begin{array}{c}W_{e} \text { evap. } \\
\mathrm{H}_{2} \mathrm{O} \text { before } \\
\text { exposure }\end{array}$ & $\begin{array}{c}W_{n} \\
\text { nonevap. } \\
\mathrm{H}_{2} \mathrm{O} \text { after } \\
\text { exposure }\end{array}$ & $\begin{array}{l}\mathrm{CO}_{2} \text { after } \\
\text { exposure }\end{array}$ & $\begin{array}{c}W_{\text {e evap. }} \\
\mathrm{H}_{2} \mathrm{O} \text { before } \\
\text { exposure }\end{array}$ & $\begin{array}{c}W_{n} \\
\text { nonevap. } \\
\mathrm{H}_{2} \mathrm{O} \text { after } \\
\text { exposure }\end{array}$ & $\begin{array}{l}\mathrm{CO}_{2} \text { after } \\
\text { exposure }\end{array}$ \\
\hline & & \multicolumn{10}{|c|}{ Percent of ignited cement } \\
\hline 0.3 & $\begin{array}{r}1 \\
2 \\
3 \\
4 \\
5 \\
6 \\
7 \\
8 \\
9 \\
10\end{array}$ & 30.6 & $\begin{array}{r}23.39 \\
22.85 \\
20.44 \\
17.67 \\
14.84 \\
7.99 \\
4.39 \\
2.92 \\
0 \\
\end{array}$ & $\begin{array}{r}10.00 \\
9.29 \\
8.90 \\
8.28 \\
7.15 \\
5.28 \\
7.53 \\
7.77 \\
7.99 \\
10.68\end{array}$ & $\begin{array}{r}4.28 \\
5.35 \\
6.49 \\
9.36 \\
13.39 \\
22.76 \\
2.59 \\
1.49 \\
0.82 \\
.41\end{array}$ & $\begin{array}{r}20.60 \\
20.62 \\
18.80 \\
17.11 \\
15.10 \\
8.75 \\
4.08 \\
2.17 \\
0\end{array}$ & $\begin{array}{r}10.96 \\
11.10 \\
10.40 \\
10.27 \\
9.12 \\
7.44 \\
6.21 \\
10.57 \\
10.60 \\
11.65\end{array}$ & $\begin{array}{r}2.33 \\
2.32 \\
4.13 \\
6.16 \\
8.56 \\
15.78 \\
21.85 \\
1.81 \\
0.98 \\
.45\end{array}$ & $\begin{array}{r}19.07 \\
19.11 \\
17.82 \\
16.21 \\
13.62 \\
9.42 \\
5.66 \\
3.61 \\
0\end{array}$ & $\begin{array}{l}12.94 \\
12.67 \\
12.61 \\
12.06 \\
10.46 \\
10.02 \\
10.95 \\
13.32 \\
12.99 \\
13.15\end{array}$ & $\begin{array}{r}1.08 \\
1.21 \\
2.34 \\
3.64 \\
6.57 \\
10.80 \\
8.23 \\
3.27 \\
1.10 \\
0.44\end{array}$ \\
\hline 0.4 & $\begin{array}{r}1 \\
2 \\
3 \\
4 \\
5 \\
6 \\
7 \\
8 \\
9 \\
\mathbf{1 0}\end{array}$ & 40.3 & $\begin{array}{r}32.89 \\
32.41 \\
25.81 \\
18.61 \\
13.52 \\
5.18 \\
2.73 \\
1.79 \\
0\end{array}$ & $\begin{array}{r}9.76 \\
9.76 \\
7.77 \\
6.46 \\
5.43 \\
7.42 \\
7.54 \\
7.55 \\
7.77 \\
12.36\end{array}$ & $\begin{array}{r}8.02 \\
9.15 \\
16.63 \\
24.90 \\
33.85 \\
30.04 \\
14.77 \\
1.34 \\
0.91 \\
.40\end{array}$ & $\begin{array}{r}29.36 \\
29.42 \\
27.14 \\
24.01 \\
20.28 \\
11.29 \\
5.56 \\
3.68 \\
0\end{array}$ & $\begin{array}{r}12.42 \\
12.28 \\
12.23 \\
10.89 \\
9.94 \\
7.37 \\
11.52 \\
11.95 \\
12.41 \\
13.64\end{array}$ & $\begin{array}{r}3.38 \\
3.77 \\
5.15 \\
8.84 \\
13.98 \\
26.50 \\
7.75 \\
1.86 \\
1.15 \\
0.43\end{array}$ & $\begin{array}{r}28.43 \\
28.52 \\
26.17 \\
23.16 \\
19.44 \\
9.69 \\
4.90 \\
3.08 \\
0\end{array}$ & $\begin{array}{r}14.37 \\
14.53 \\
13.36 \\
12.61 \\
11.05 \\
8.16 \\
13.63 \\
14.01 \\
14.62 \\
14.73\end{array}$ & $\begin{array}{r}1.80 \\
1.79 \\
4.68 \\
8.07 \\
13.62 \\
26.79 \\
5.14 \\
1.94 \\
1.35 \\
0.45\end{array}$ \\
\hline 0.5 & $\begin{array}{r}1 \\
2 \\
3 \\
4 \\
5 \\
6 \\
7 \\
8 \\
9 \\
10\end{array}$ & 47.8 & $\begin{array}{r}39.64 \\
39.59 \\
29.86 \\
18.61 \\
8.01 \\
1.94 \\
2.06 \\
0.43 \\
0\end{array}$ & $\begin{array}{r}9.50 \\
9.45 \\
6.35 \\
4.95 \\
4.37 \\
7.13 \\
7.12 \\
7.17 \\
7.18 \\
13.31\end{array}$ & $\begin{array}{r}10.40 \\
10.87 \\
23.11 \\
37.32 \\
38.13 \\
1.59 \\
1.07 \\
0.98 \\
1.06 \\
0.47\end{array}$ & $\begin{array}{r}36.02 \\
36.11 \\
31.89 \\
26.90 \\
21.21 \\
9.36 \\
4.57 \\
3.28 \\
0\end{array}$ & $\begin{array}{r}13.64 \\
13.46 \\
12.68 \\
10.43 \\
9.04 \\
6.92 \\
13.02 \\
13.02 \\
12.80 \\
14.88\end{array}$ & $\begin{array}{r}5.40 \\
5.46 \\
9.11 \\
16.07 \\
25.63 \\
40.65 \\
2.64 \\
1.80 \\
1.23 \\
0.49\end{array}$ & $\begin{array}{r}33.76 \\
33.82 \\
30.45 \\
26.13 \\
20.72 \\
8.95 \\
4.77 \\
2.94 \\
0\end{array}$ & $\begin{array}{r}14.70 \\
14.70 \\
13.88 \\
12.69 \\
10.56 \\
8.15 \\
14.80 \\
14.72 \\
14.98 \\
15.62\end{array}$ & $\begin{array}{r}3.76 \\
4.15 \\
6.92 \\
13.00 \\
22.35 \\
35.84 \\
3.01 \\
2.07 \\
1.52 \\
0.50\end{array}$ \\
\hline $\begin{array}{c}0.5 \\
\mathrm{CaCl}_{2} \\
\text { added }\end{array}$ & $\begin{array}{r}1 \\
2 \\
3 \\
4 \\
5 \\
6 \\
7 \\
8 \\
9 \\
10\end{array}$ & 49.3 & $\begin{array}{r}39.86 \\
39.84 \\
30.76 \\
19.64 \\
11.93 \\
3.79 \\
2.36 \\
1.94 \\
0\end{array}$ & $\begin{array}{r}12.34 \\
12.22 \\
10.67 \\
7.19 \\
6.23 \\
9.45 \\
9.43 \\
9.34 \\
9.21 \\
15.63\end{array}$ & $\begin{array}{r}8.83 \\
9.14 \\
17.12 \\
32.05 \\
36.87 \\
3.14 \\
2.12 \\
1.83 \\
1.42 \\
0.65\end{array}$ & $\begin{array}{r}36.51 \\
36.59 \\
32.15 \\
26.16 \\
18.79 \\
9.82 \\
5.50 \\
4.12 \\
0\end{array}$ & $\begin{array}{r}13.85 \\
14.30 \\
12.92 \\
11.59 \\
9.19 \\
6.88 \\
13.61 \\
13.63 \\
15.31\end{array}$ & $\begin{array}{r}4.61 \\
4.82 \\
9.80 \\
18.20 \\
30.05 \\
39.08 \\
3.22 \\
2.43 \\
1.61 \\
0.50\end{array}$ & $\begin{array}{r}35.61 \\
35.77 \\
32.13 \\
25.51 \\
20.28 \\
9.55 \\
6.19 \\
3.76 \\
0\end{array}$ & $\begin{array}{r}15.40 \\
15.49 \\
14.56 \\
12.35 \\
10.91 \\
7.94 \\
15.84 \\
15.84 \\
15.95 \\
16.42\end{array}$ & $\begin{array}{r}3.31 \\
3.37 \\
7.20 \\
15.88 \\
25.95 \\
40.33 \\
3.17 \\
2.63 \\
1.90 \\
0.60\end{array}$ \\
\hline
\end{tabular}
dioxide content after exposure 


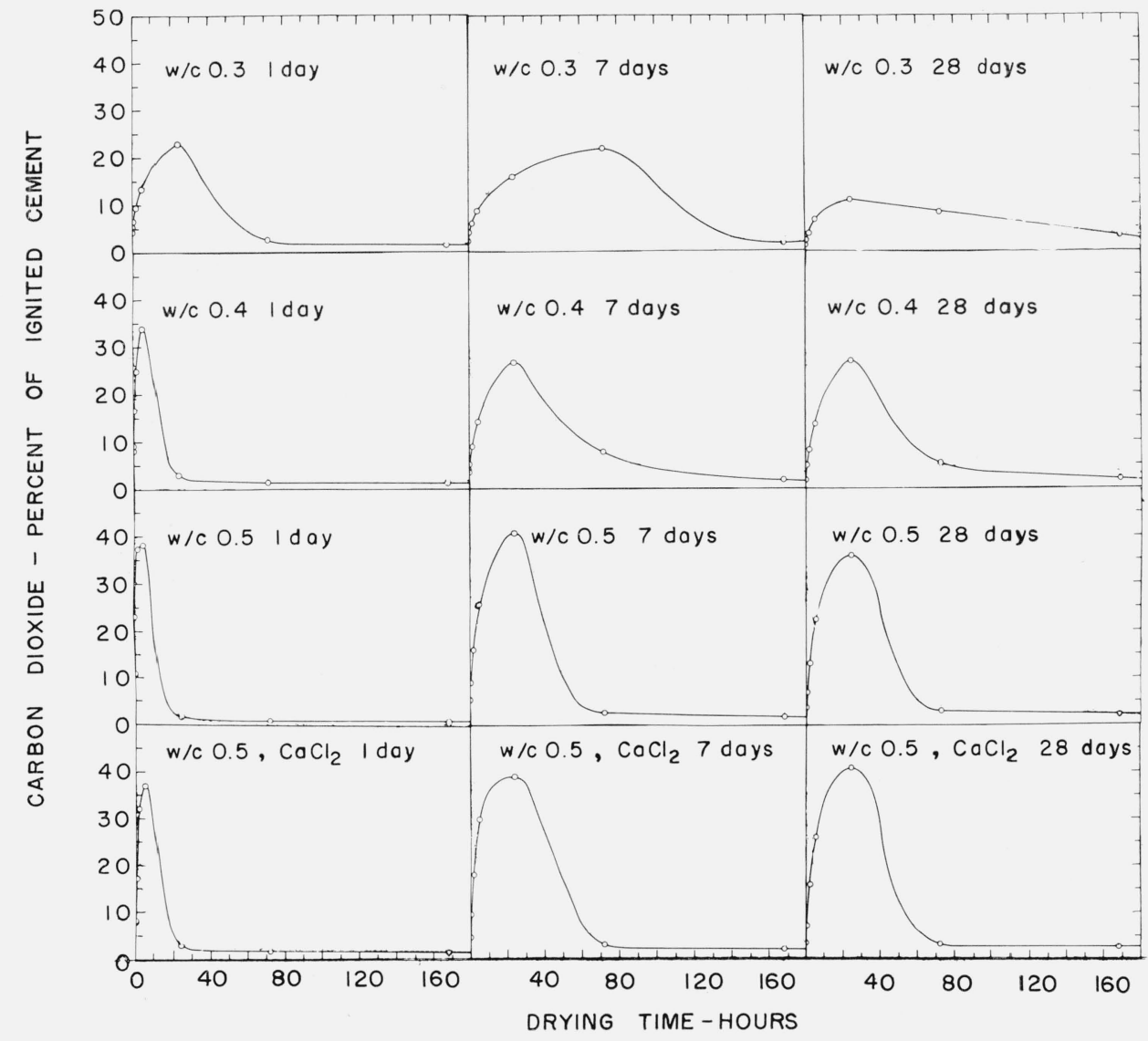

FIGURE 2. Carbon dioxide content of cement pastes as a function of drying time before exposure to carbon dioxide.

cement ratio is represented by a separate curve. For each paste there is an optimum condition for maximum reaction with carbon dioxide. Sevenday-old pastes are denser in structure and dry more slowly than 1-day-old pastes. Therefore they reach and pass through this optimum condition more slowly. This difference is evident from the shift of the maxima of the curves in figure 2. This shift would be expected to be greater in older specimens. However, the 28-day-old specimens do not appear to reach the optimum condition more slowly than 7-day specimens. The amount of additional hydration of these particular specimens between 7 and 28 days is apparently insufficient to make a significant change in their drying and carbonation characteristics, except in the very dense paste of water-cement ratio 0.3 . At this water-cement ratio, reduced accessibility to carbon dioxide at 28 days is the predominant effect.

In general, young pastes of high water-cement ratio tend to carbonate more readily than older and denser pastes. For example, a 28-day-old specimen of water-cement ratio 0.3 would react with less carbon dioxide than a 1-day-old specimen of water-cement ratio 0.5 , but if the comparison is arbitrarily made after $72 \mathrm{hr}$ of drying, rather than at the time of maximum reaction, the opposite is true. Behavior such as this is probably one of the reasons why Leber and Blakey [9] were induced to comment that, "There is ample evidence that slight changes in carbon dioxide treatment, such as age at which treatment starts, will produce completely contradictory results."

The effect of calcium chloride was examined at one water-cement ratio, because it is a commonly used agent for accelerating the hydration of portland cement. It might be expected that a 1-day-old paste containing calcium chloride might behave as a slightly older specimen without calcium chloride. However, the two sets of curves in figure 2, representing water-cement ratio 0.5 with and without calcium choloride, show only slight differences. Apparently the reduction in bleeding produced by the accelerator has compensated for any increased hydration. In other words more hydration products are formed in the presence of calcium chloride, but there is also more space to fill. Therefore the net affect on the drying and carbonation characteristics of the paste is small.

\subsection{Carbonation as a Function of Pore Space}

Powers and Brownyard [18] have designated the pores remaining in the voids between the original particles, which become partially or completely filled with gel during hydration, as capillary pores. The 
much smaller pores characteristic of the gel they have designated as gel pores. The sum of the capillary and gel pore space is the total pore space.

The pore volume of a saturated paste is equal to the volume of water required to fill the pores. For purposes of approximation, pore volume, in appropriate units, may be considered numerically equal to the weight or percentage of water required to fill the pores, since water in a saturated paste has a specific volume of 0.99 [19]. In order to examine carbonation from the standpoint of pore space, carbon dioxide content at the end of one week exposure is plotted in figure 3 as a function of the amount of evaporable water in the specimen at the start of exposure. For each hardened paste before carbonation the amount of the original mixing water, $W_{o}$, the total pore volume, $P_{T}$, and the volume of the gel pores, $P_{G}$, are marked on the abscissa of the graph. The difference between $P_{T}$ and $P_{G}$ on the abscissa is approximately numerically equal to the capillary pore volume in $\mathrm{cm}^{3} / 100 \mathrm{~g}$ of cement, and the difference between $W_{o}$ and $P_{T}$, to the net increase in the volume of solid phases during hydration. Figure 3 affords a visual comparison of the amount of evaporable water in each specimen at the beginning of each carbonation experiment and the amount of

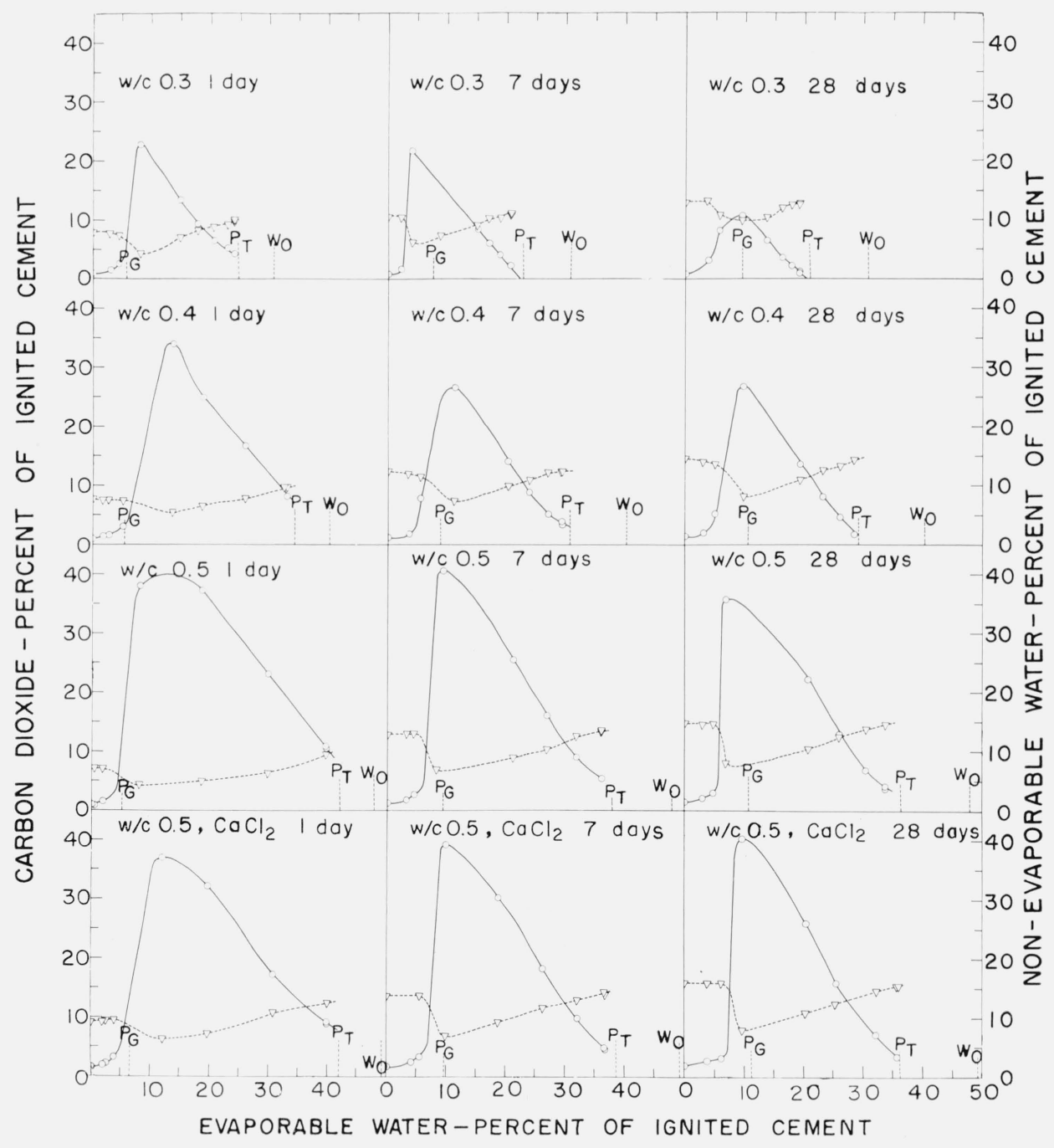

FIGURE 3. Carbon dioxide and nonevaporable water content of cement pastes as a function of the evaporable water content of the pastes as determined before exposure to carbon dioxide.

Carbon dioxide content after a week of exposure to carbon dioxide

Nonevaporable water content after a week of exposure to carbon dioxide

$P_{G}$ Volume of gel pores

$P_{T}$ Total pore volume

$W_{o}$ Original water content of the fresh paste. 


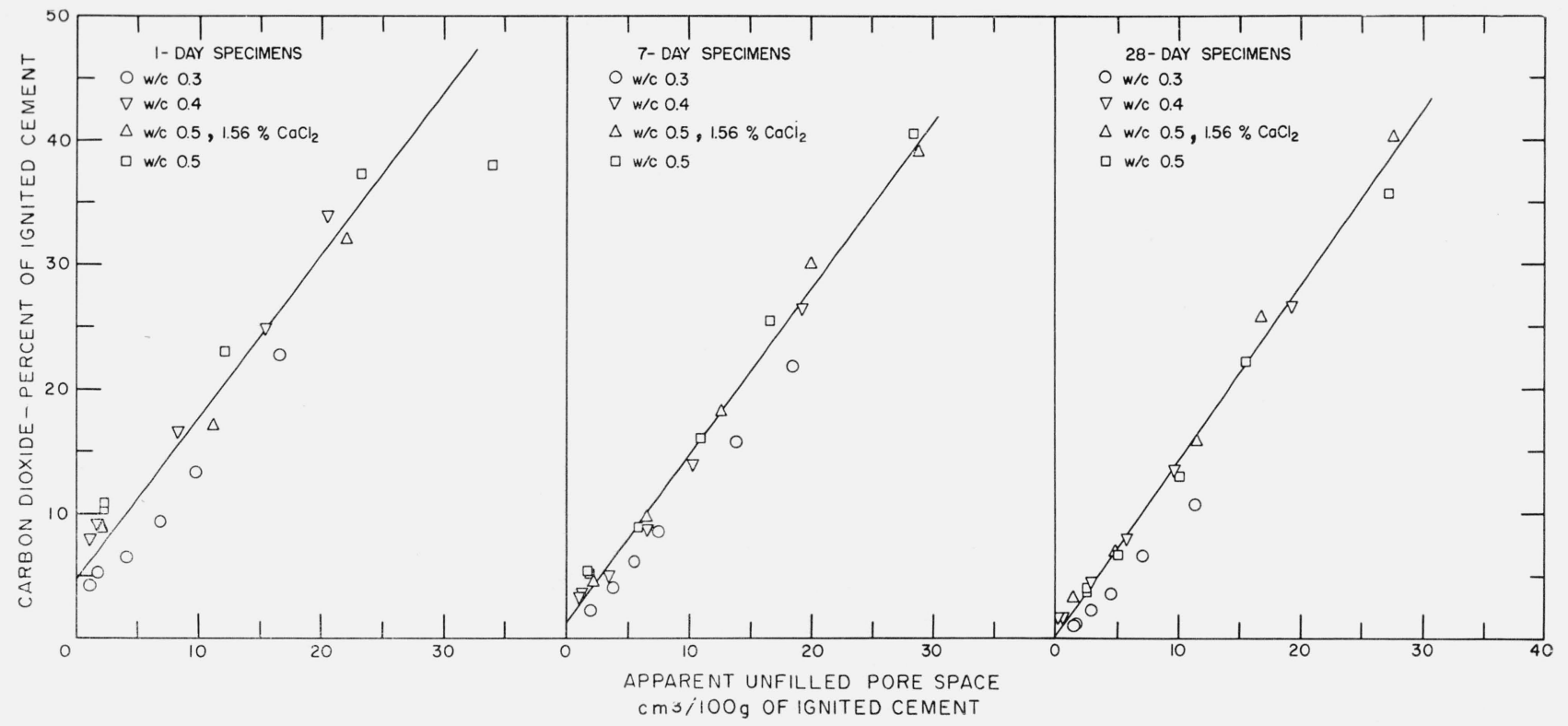

FIGURE 4. Carbon dioxide content of cement paste as a function of apparent unflled pore space at the beginning of carbo nation.

water required to fill the pores. The difference along the abscissa between each point and the value of $P_{T}$ is approximately equal to the unfilled pore space in $\mathrm{cm}^{3} / 100 \mathrm{~g}$ of cement. Since less is known about the actual volume of the pores and the density of water in a partially dried paste than in a saturated paste, the value obtained is referred to in this paper as apparent uniflled pore space.

Considering only the right branch of each solid curve in figure 3 , the amount of carbon dioxide in each specimen shows rather good correlation with the apparent unfilled pore volume at the beginning of carbonation. In figure 4 the data for 1-day-old specimens of all water-cement ratios is assembled in one graph, and the same is done for 7 - and 28-day-old specimens.

Differences between pastes of different watercement ratio may be seen in figure 4 , but they are small considering the much greater possibility for loss of continuity of the capillary pores in denser pastes. According to estimates of Powers, Copeland, and Mann [20], based upon water-permeability measurements of saturated pastes, all of the specimens of water-cement ratio 0.3 and the 7 - and 28-day-old specimens of water-cement ratio 0.4 might reasonably be expected to have completely lost their capillary continuity. However, when these specimens were dried and exposed to carbon dioxide, they behaved comparably to specimens of higher watercement ratio which should definitely contain continuous capillary pores. Powers [21] has reported a 70-fold increase in the water permeability coefficient of a mature paste after bringing it to equilibrium with 79 percent relative humidity and carefully resaturating it. Therefore it is not surprising that partially dried pastes of low water-cement ratio should have considerable accessibility to carbon dioxide. Even if capillary continuity is lost in the hydration process, drying apparently creates passages.

\subsection{Carbonation and Nonevaporable Water}

Carbonation brings about a reduction in the amount of chemically combined water in hardened cement paste. In figure 3 this reduction is reflected by decreases in nonevaporable water shown by the dotted lines in the figure. It should be possible to draw some inferences as to whether calcium hydroxide is the only phase involved in carbonation by determining the amount of nonevaporable water lost during the process. Verbeck [10] has applied a somewhat analogous procedure to the analysis of autoclaved pastes. The reaction of calcium hydroxide with carbon dioxide may be represented by the equation,

$$
\mathrm{Ca}(\mathrm{OH})_{2}+\mathrm{CO}_{2} \rightarrow \mathrm{CaCO}_{3}+\mathrm{H}_{2} \mathrm{O}
$$

One molecule of water is released for every molecule of carbon dioxide accounted for in the final product. While calcium bicarbonate as a possible intermediate product should not be overlooked [8a], the analysis includes only carbonate stable during the final drying. Equation 3 is therefore a reasonable representation of the initial reactants and final products in the carbonation of calcium hydroxide. It is more difficult to write equations representing the carbonation of other phases in hardened cement paste. However, if less than one molecule of water is released from the paste for every molecule of carbon dioxide gained, and if hydration of the cement goes on at a negligible rate, it is clear that calcium hydroxide is not the only phase attacked in the carbonation process. If, on the other hand, equimolecular stoichiometry is observed, it is possible that calcium hydroxide is the only phase attacked, but the point is not unequivocally proven until more information is known about the behavior of other phases during carbonation and drying. 


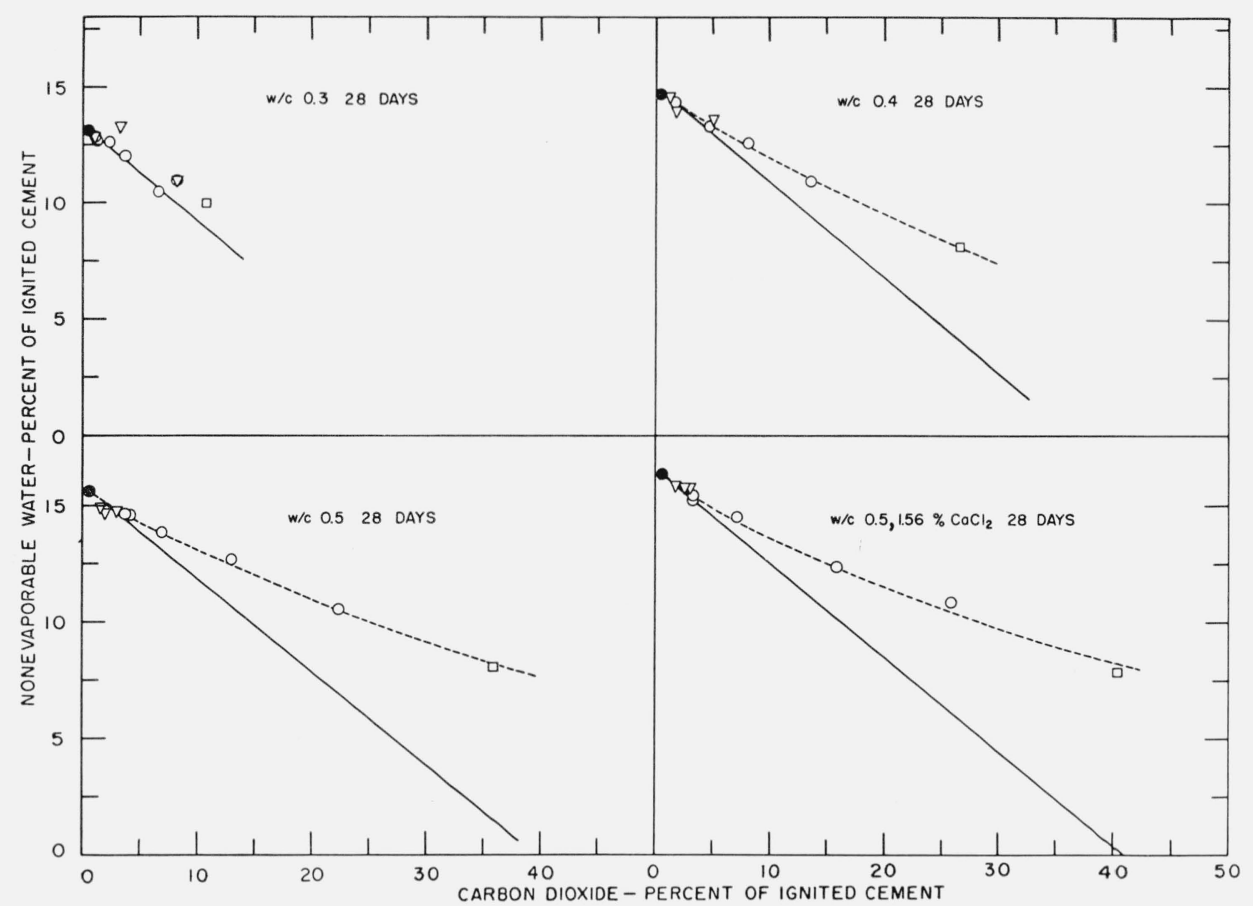

Figure 5. Nonevaporable water content of cement paste as a function of carbon dioxide content.

In figure 5 the nonevaporable water contents of 28-day-old specimens are plotted as a function of carbon dioxide content. By limiting the analysis to 28-day-old pastes, hydration during the carbonation period is limited to less than 0.5 percent nonevaporable water. The solid straight lines in figure 5 correspond to the required theoretical slope if one molecule of water is lost for every molecule of carbon dioxide gained. Comparison of the experimental points with the theoretical slope shows that less water was released than required by the stoichiometry of eq 3, except in the paste of water-cement ratio 0.3 or at low levels of carbonation in the other pastes.

Verbeck [10] has estimated that it would be stoichiometrically possible to account for carbon dioxide contents equivalent to about 20 percent or more of ultimate carbonation by reaction with calcium and alkali hydroxides without attack on the main gel phases. Of course any such estimate depends upon the degree of hydration, since calcium hydroxide is one of the hydration products. For the cement represented in figure 5, 20 percent of ultimate carbonation corresponds to about 10 percent carbon dioxide based on the ignited weight of the cement. The form of the experimental curves for the pastes of water-cement ratios 0.4 and 0.5 suggests that there is some possibility of preferential attack on calcium hydroxide, particularly in the early stages of carbonation, but that other phases react while calcium hydroxide is still present. The data for paste of water-cement ratio 0.3 more nearly approximate the theoretical slope than the data for other pastes. From the point of view of $\mathrm{CO}_{2}-\mathrm{H}_{2} \mathrm{O}$ stoichiometry, this paste resembles autoclaved neat pastes [10]. A 28-day-old paste of water-cement ratio 0.3 would have a much lower surface area, as measured by nitrogen adsorption, than pastes of higher water-cement ratio. Autoclaved pastes have even lower surface areas. This factor seems to make a difference in the relative accessibility of the different phases to carbon dioxide.

\subsection{Depth of Carbonation}

In figure 6 the carbon dioxide content of four unidirectionally dried and exposed cylinders of paste is plotted as a function of average sampling depth. The A specimen, which was dried $30 \mathrm{~min}$ before exposure, showed only superficial carbonation after a week of exposure. The carbon dioxide content was already rather low at an average sampling depth of $5 \mathrm{~mm}$. Longer drying resulted in deeper penetration into the paste. Specimen $\mathrm{C}$, which was dried 48 $\mathrm{hr}$, is of particular interest because it contained more carbon dioxide at a depth of $30 \mathrm{~mm}$ than near the surface. The specimen which was dried a week before exposure was too dry for optimum reaction. If any high-carbonation zone existed further inside the specimen, it was beyond the maximum sampling depth of about $38 \mathrm{~mm}$. 


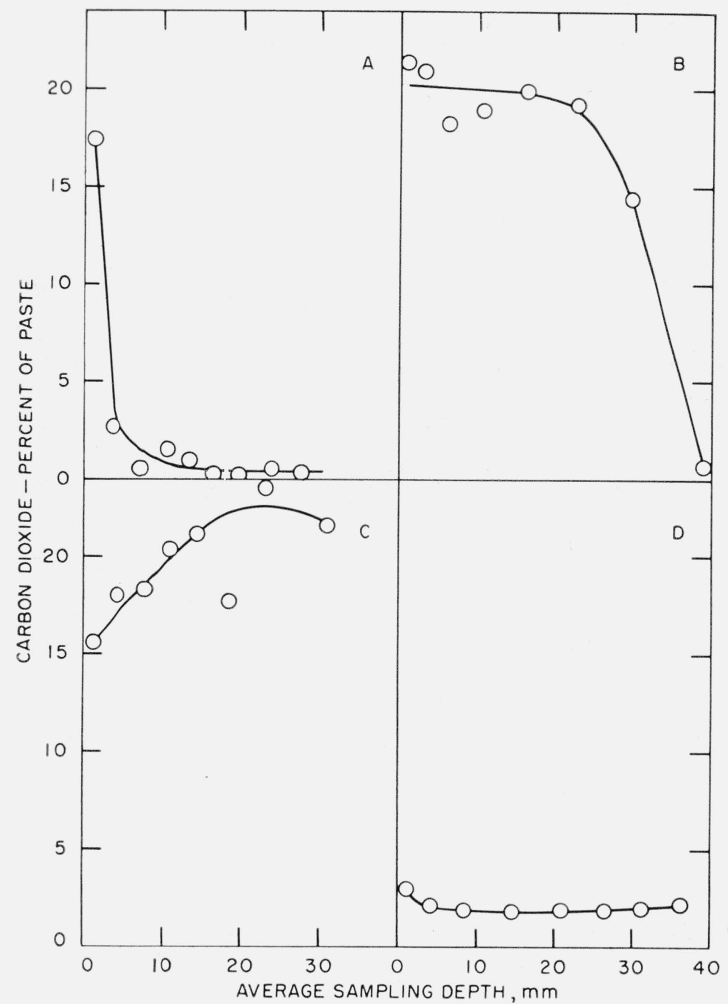

Figure 6. Depth of carbonation.

Drying time before exposure, A-30 min., B-6 hr., C-48 hr., D-1 week. A, B, and C exposed simultaneously in same chamber, D exposed separately.

Since reaction with carbon dioxide is influenced by the moisture content of the paste, a moisture gradient in a reacting specimen leads to different rates of carbonation in different parts of the specimen. Figure 6 is an experimental demonstration of this fact for a particular set of conditions. Gradients in moisture and carbon dioxide content probably existed also in the $1 / 2$-in. specimens represented in figures 2, 3, 4, and 5. However, except for the wetter specimens, such gradients were probably small in comparison with those attained with larger specimens.

\subsection{Carbonation and the Physical Characteristics of Hydrated Cement}

In the results shown in figures 2 to 5 , the water and carbon dioxide involved in the carbonation process have been accounted for, but no direct information has been obtained regarding the effect of carbonation on the compressive strength, shrinkage, or other physical properties or behavior of hardened paste. The physical characteristics of the product may depend not only on the amount of carbonate formed but also on the conditions under which it is formed. For example, Zalmanoff [22] found that the strengths of carbonated lime putties were greater if carbonation and drying took place simultaneously than if the specimens were first dried and then exposed to carbon dioxide. Possibly similar behavior might be observed with cement products. The effect of sequence of drying and carbonation on shrinkage is less clear. Verbeck [10] found that mortar specimens shrank more if they were first dried at 50 percent relative humidity and then exposed to carbon dioxide than if carbonation and drying took place simultaneously. However, Alexander and Wardlaw [23] concluded from the study of small specimens of paste, $1 / 8 \mathrm{in}$. in diameter and 2 in. long, that the sequence of drying and exposure made little difference. In the present experiments the drying characteristics of the specimens after carbonation indicated small differences in permeability, depending on the amount of water in the specimens at the beginning of carbonation. Specimens which were nearly saturated when exposed to carbon dioxide appeared to dry more slowly in vacuum thereafter than specimens which contained less water. When the specimens were crushed, the differences in drying rate were largely eliminated. These qualitative observations of the drving characteristics of carbonated pastes suggest that optimum conditions for reaction with $\mathrm{CO}_{2}$ might not necessarily be optimum conditions for producing densetextured reaction products.

\section{Summary}

Partially dried $1 / 2-i n$. cylinders of paste of nominal water-cement ratio $0.3,0.4$, and 0.5 reacted with increasing amounts of carbon dioxide as the watercement ratio increased. The differences in the amounts of carbon dioxide reacting were greater at 28 days than at one day. However, pastes of different age and water-cement ratio tend to dry at different rates and reach, or go beyond, optimum conditions for carbonation at different rates. Under some circumstances this behavior can overshadow any inherent differences in reactivity or accessibility to carbon dioxide.

In pastes containing more than the optimum amount of evaporable water for carbonation the amount of carbon dioxide found after a week of exposure showed a linear relationship with the apparent unfilled pore volume at the beginning of carbonation.

Analysis of 28-day-old specimens showed that less than one molecule of water was released for every molecule of carbon dioxide gained, except in a paste of $\mathrm{w} / \mathrm{c}$ ratio 0.3 and at low levels of carbonation in other pastes. This behavior does not rule out the possibility of some preferential attack on calcium hydroxide, but shows that other phases can react while calcium hydroxide is still present. Apparently in a very dense paste of low water-cement ratio the comparative accessibility of the various phases to carbon dioxide is different than in a paste of high ratio.

The effect of moisture gradients on the depth of carbonation was examined with unidirectionably dried cylinders, $1 \mathrm{in}$. in diameter and $2 \frac{1}{2} \mathrm{in}$. long. One of the predried specimens was found to have more carbonate formed at a depth of 2 to $3 \mathrm{~cm}$ than nearer the exposed surface. 
The authors gratefully acknowledge the assistance of Vernon Dantzler in some of the measurements reported here.

\section{References}

[1] Annual Report Building Research Board, (1932), p. 34 Dept. of Scientific and Ind. Research, His Majesty's Stationery Office, London, (1933).

[2] G. E. Bessey, Soc. Chem. Ind. J. 52, 287-293T (1933).

[3] F. L. Brady, Cement and Cement Mfgr. 4, 1105-1109 (1931).

[4] F. E. Jones, Weathering Tests on Asbestos-Cement Roofing Materials, Dept. Scientific and Ind. Research, RP29, His Majesty's Stationery Office (1947).

[5] S. L. Meyers, Rock Products 52, 96-98 (1949).

[6] F. M. Lea and C. H. Desch, The Chemistry of Cement and Concrete, p. 328, London, Edward Arnold Co., (1935).

[7] J. A. Kauer and R. L. Freeman, Proc. Am. Concrete Inst. 52, 447-454 (1955).

[8] F. M. Lea, The Chemistry of Cement and Concrete, revised ed. of Lea and Desch, pp. (a.) 287-294; (b) 473-475, St. Martin's Press, (1956).

[9] I. Leber and F. A. Blakey, Proc. Am. Concrete Inst. 53, 295-308 (1950).

[10] George Verbeck, Carbonation of Hydrated Portland Cement, Am. Soc. Testing Materials Special Tech. Publ. No. 205 .
11] H. T. Toennies, Proc. Am. Concrete Inst. 56, 737-755 (1960)

[12] B. Kroone and F. A. Blakey, Proc. Am. Concrete Inst. 56, 497-510 (1959).

[13] C. R. Hutcheroft and H. R. Anderson, Proc. Am. Concrete Inst. 3\%, 597-604 (1941).

[14] L. E. Copeland and J. C. Hayes, Am. Soc. Testing Materials Bull. 194, p. 70 (1953); also Portland Cement Assoc. Bull. No. 47.

[15] I. M. Kolthoff and E. B. Sandell, Textbook of Quantitative Inorganic Analysis, 3d ed., p. 373, The MacMillan Co., New York (1952).

[16] C. M. Hunt, V. Dantzler, L. A. Tomes, and R. L. Blaine, J. Research NBS 60, 441-446 (1958) RP2858.

[17] L. E. Copeland and J. C. Hayes, Proc. Am. Concrete Inst. 52, 633-640 (1956).

[18] T. C. Powers and T. L. Brownyard, Proc. Am. Concrete Inst, 43, 971-992 (1947), Portland Cement Assoc. Bull. No. 22.

[19] L. E. Copeland, Proc. Am. Concrete Inst. 52, 863-874 (1956); Portland Cement Assoc. Bull. No. 75.

[20] T. C. Powers, L. E. Copeland, H. M. Mann, J. Portland Cement Assoc. Dev. Lab. 1, 38-48 (1959).

[21] T. C. Powers, 4th International Symp. Chemistry of Cement, (1960)

[22] Nissan Zalmanoff, Rock Products 59, 182-186 (1956).

[23] K. M. Alexander and J. Wardlaw, Australian J. Appl. Sci. 10, 470-483 (1959).

(Paper 66A6-182) 